\title{
AS PRÁTICAS PEDAGÓGICAS E O LÚDICO NA EDUCAÇÃO INFANTIL
}

\author{
Cátia Cristine Silva da Cruz Nascimento ${ }^{1}$ \\ Dalvelice Borges dos Santos ${ }^{2}$
}

\section{Resumo}

Este capítulo apresenta uma discussão sobre as práticas pedagógicas e o lúdico na educação infantil com abordagens sobre a identidade do professor da educação infantil e o seu fazer docente seguida de reflexões acerca do conflito entre a teoria e prática, os obstáculos e desafios do ser professor destacando a importância da formação continuada para a prática pedagógica. Através dessas abordagens propõe analisar a ludicidade nas práticas pedagógicas ressaltando a contribuição das aprendizagens na Educação Infantil, para elucidar os subsídios que a ludicidade promove para a aprendizagem nessa modalidade de ensino. A pesquisa apresenta discussão bibliográfica sobre a funcionalidade dessa modalidade refletindo sobre a identidade do professor que atua com crianças de 0 a 05 anos. Conclui-se que as práticas pedagógicas constituem-se como meios de alcançar os objetivos da Educação Infantil sendo relevantes as atividades lúdicas que promovem uma atividade significativa e prazerosa.

Palavras Chaves: Práticas pedagógicas. Lúdico. Educação Infantil.

\section{Abstract}

This chapter presents a discussion on the pedagogical and playful practices in early childhood education with approaches on the identity of the early childhood teacher and his teaching practice followed by reflections on the conflict between theory and practice, the obstacles and challenges of being a teacher highlighting the importance of continuing education for pedagogical practice. Through these approaches, it proposes to analyze playfulness in pedagogical practices, emphasizing the contribution of learning in Early Childhood Education, to elucidate the subsidies that playfulness promotes for learning in this type of teaching. The research presents bibliographic discussion about the functionality of this modality reflecting on the identity of the teacher who works with children from 0 to 05 years old. It is concluded that the pedagogical practices are constituted as means to reach the objectives of the Infantile Education being relevant the ludic activities that promote a meaningful and pleasant activity.

Keywords: Pedagogical practices. Ludic. Child education.

\section{Introdução}

\footnotetext{
1 Mestra em Ciências da Educação pela Faculdade Interamericana Ciências Sociales - FICS. Especialista em Docência na Educação Infantil pela Universidade Federal da Bahia - UFBA; Graduada em Pedagogia com Habilitação em Gestão Educacional pela FAC. Docente na Educação Infantil pela Secretaria Municipal de Educação no município de Candeias/Ba. E-mail: caty_nascimento19@hotmail.com

2 Mestra em Ciências da Educação pela Faculdade Interamericana Ciências Sociales - FICS. Graduada em Pedagogia pela Universidade Estadual da Bahia - UNEB. Especialista em Metodologia do Ensino, Pesquisa e Extensão pela Universidade Estadual da Bahia - UNEB. Docente nos municípios de Salvador e Madre de Deus.
} 
A prática pedagógica do educador da Educação Infantil não é apenas transmitir os conteúdos, mas dar oportunidade para a criança pensar, questionar e levantar hipóteses, ou seja, criar condições para sua autodescoberta. As atividades nessa modalidade de ensino devem proporcionar experiências que permitam uma aprendizagem significativa numa abordagem prazerosa, culminando em atividades lúdicas.

Faz-se necessário que as escolas de Educação Infantil e os professores dessa modalidade repensem seu papel no desenvolvimento das crianças e perceba que os primeiros anos de vida são de extrema importância para a formação do ser humano. A criança é um indivíduo na sua totalidade, este fato torna cada vez mais evidente o respeito e cuidado das atividades realizadas na Educação Infantil com a criança na faixa etária de 0 a 5 anos, pois:

As atividades propostas nas instituições de Educação Infantil devem alimentar o desenvolvimento do corpo, do pensamento, da imaginação e dos sentimentos de modo a integrar as ações de cuidar e educar, proporcionando a constituição de novos e singulares interesses infantis alinhado a experiências continuas vivenciadas nesses espaços (OLIVEIRA, et. al, 2012, p.49).

Para o desenvolvimento e a socialização das crianças na Educação Infantil, é necessário compreender o quanto é valioso o trabalho com jogos. Entretanto, é imprescindível esclarecer que os jogos não devem ser empregados como mero recurso para divertir a criança, mas sim planejados com finalidades educativas. Para isso cabe aos educadores definir intencionalidades a esses antes de suas implementações, o que acarretará o desenvolvimento de inúmeras formas de inteligência na criança, e consequentemente contribuirá para o desenvolvimento infantil.

\section{Identidade do Professor da Educação Infantil}

As identidades profissionais são estabelecidas nas narrações pessoais e precisam ser incluídas como produções em espaços históricos e institucionais específicos, no interior de formações e práticas discursivas específicas, por estratégias e iniciativas específicas. No que se refere a identidade docente destacase que:

Os professores adotam-se como profissionais de ensino, no entanto não entendem as especificidades da docência no ensino infantil se apegando a transferência de conteúdos e a outras práticas mais indicadas ao ensino fundamental. Apreciam mais as atividades conduzidas do que o brincar, ou 
seja, a brincadeira ocupa um lugar subsidiário nas práticas pedagógicas (FERNANDES, 2010, p. 5).

A formação da identidade docente está relacionada aos processos de socialização e às interações sociais nas diferentes conjunturas em que o professor está inserido. É proposto o aumento dessa hipótese, articulando-a à abordagem teórica da produção da identidade cultural

Não existe outra saída a não ser da integração na diversidade de interesses não contrários dos educadores na defesa de seus direitos. Direito à sua liberdade docente, à sua fala, a melhores condições de trabalho pedagógico, a tempo livre e remunerado para dedicar à sua formação permanente, de ser coerente, de criticar as autoridades sem medo de punição a que corresponde o dever de responsabilizar-se pela veracidade de sua crítica, de ter o dever de ser sérios, coerentes, de não mentir para sobreviver (FREIRE, 1993).

O professor que optar por atender as crianças da Educação Infantil deve compreender a necessidade de seguir as orientações e diretrizes que norteiam a Educação Infantil. Os saberes presentes na prática docente são de natureza social, e as relações que os professores estabelecem com os saberes oriundos da formação profissional, disciplinares, curriculares e experienciais podem variar entre si.

Predomina o conjunto de saberes produzido pelo professor no exercício de sua prática, no decorrer de sua carreira, são os saberes específicos, não que provêm das instituições de formação nem dos currículos, mas fruto de sua experiência (TARDIF, 2000).

Os profissionais que atuam na Educação Infantil devem além de buscar uma atualização de sua formação profissional, necessitam valorizar as aprendizagens que ocorrem com a socialização com as crianças. Os programas de formação docente para Educação Infantil hoje têm como importante tarefa ajudar os professores a saírem do lugar de mudança de discursos para mudança de procedimentos e atitudes, buscando sensibilizar os professores quanto a importância de uma formação adequada para desenvolver as habilidades necessárias para as crianças dessa faixa etária. 
Ao referir-se à formação do professor na perspectiva da construção e valorização de suas identidades, refere-se a um procedimento que deve se encerrar na possibilidade da construção de uma identidade que contribua para o exercício da atividade docente. Exercer a docência, portanto, não deveria estar voltado apenas a ter conhecimentos científicos especializados de uma área definida, ou deterem-se as atividades burocráticas próprias dessa profissão (TORRES e CARNEIRO, 2014).

Faz-se necessário lapidar os profissionais para atuarem nesse espaço, profissionais que devem ser educadores com uma formação alicerçada em conhecimentos humanos, a fim de contribuir para o desenvolvimento integral da criança nas esferas motora, cognitiva e afetiva. Considerada como a mais importante a noção de que a ludicidade se torna algo natural à criança, servindo como grande fator motivador para seu envolvimento.

As ações educativas na educação infantil como múltiplas funções agenceiam múltiplos saberes e compõem múltiplas identidades, exigindo a superação de práticas que engessam a ação docente na Educação Infantil às vezes como cuidado e em outros momentos como educação, em seus sentidos limitados (FERNANDES, 2010).

A apreensão de múltiplas funções reconhece as práticas pedagógicas na Educação Infantil para além dessas dimensões, admitindo que se faça mais que ensinar e cuidar; percebe suas ações como de educação e cuidado de formas dissociadas, nas quais se requer dos profissionais desse segmento conhecimentos variados e práticas lúdicas. É importante destacar que:

A prática pedagógica exige instrumentos básicos para o aperfeiçoamento do trabalho do professor, ferramentas como a observação, o registro e problematização que podem ajudá-lo na reflexão de sua prática pedagógica. A observação permite descobrir coisas novas, pois, permite interpretar, reparar, notar, entre outras ações. Enquanto o registro possibilita a elaboração de caminhos de diálogo e de provocações construtivas de um novo saber. Já a problematização, implica em avaliar o que foi observado e registrado buscando avaliar o trabalho compreendendo melhor a si mesmo e os que o rodeiam (OLIVEIRA, et. al, 2012, p. 385 - 380).

Diante do exposto, e comparando com a prática exercida pela pesquisadora, observa-se a renovação dos conceitos sobre a docência, pois, o contato com teorias que antes desconhecia e a transformação de sua prática através de novas metodologias demonstram que o exercício da profissão por si só não favorece uma 
prática pedagógica adequada, são novos conhecimentos e novos afazeres a compartilhar com os alunos.

\section{O Fazer Docente: Conflito Entre Teoria e Prática}

Ser educador implica numa constante busca em crescer, se desenvolver e se reinventar constantemente, na perspectiva de uma melhor e mais completa compreensão possível do real significado de ensinar, transmitir conhecimento e ser um elo diário entre seus educandos e o mundo que os cerca.

O fazer docente requer contínua reflexão sobre os métodos utilizados em sala de aula, os resultados obtidos com os mesmos - se foram satisfatórios ou não - e ainda a relação e comunicação com todos os alunos. Isso é algo que por sua vez, é considerado de extrema relevância para um trabalho satisfatório tanto para o educador que se vê diante de frequentes desafios em estimular, motivar e criar caminhos que viabilizem o fazer docente e cheguem aos objetivos traçados, com também para os educandos que necessitam sentir-se bem atendidos e satisfeitos com as informações e aprendizados adquiridos.

No seu fazer docente além da formação que educador obteve no seu primeiro momento de graduação voltado para o seu exercício docente, onde possibilitou caminhos e possibilidades para que o mesmo inicie sua jornada profissional e o conhecimento sobre os diversos estudiosos, pesquisadores e teóricos no campo educacional ele precisa colocar em pratica tudo aquilo que conheceu e aprendeu na teoria.

Em seu cotidiano, o educador se vê constantemente cercado de desafios, questionamentos e muitos obstáculos que por diversas vezes pode chegar a fazê-lo desanimar, repensar sobre a sua escolha profissional e ainda o fazendo sentir-se incapaz de superar tantos entraves que persistem e existi na educação. A partir de tudo isso, se torna inevitável, frequentes e incessantes conflitos que o acompanham cotidianamente tanto dentro como também fora da instituição escolar, situações que inquieta e traz insatisfação.

Destaca-se também alguns aspectos fundamentais da formação inicial onde estão os saberes da profissão e o desenvolvimento da identidade profissional, onde, o trabalho do professor na escola requer um leque amplo de saberes para atuar em uma multiplicidade de ambientes e situações pertinentes ao campo profissional. 
Com isso entende-se que os conhecimentos que o professor possui, não vem a ser algo específico, mas composto por vários saberes, oriundos de diferentes campos do conhecimento e que podem dar conta da pluralidade de tarefas e perspectivas de educação.

O professor vivencia situações, busca solucionar problemas existentes com seus educandos e traça planos pertinentes não somente a transmitir conteúdos, mas também o ato de preparar seus alunos para a vida em sociedade, onde irá transitar em diferentes meios sociais, o que implicará em ter embasamento para o exercício da cidadania e conhecimentos relevantes para o seu crescimento e desenvolvimento em diversos aspectos da vida.

Ao abordar sobre o educador em sua totalidade, existe a busca pela sua identidade profissional, conquista de autonomia, onde exige segurança, convicção e disposição para diversos enfrentamentos, será questionado algumas vezes acerca da sua atuação em sala de aula, interrogado sobre o método que utiliza.

Esses questionamentos geram momentos conflitantes de se pensar em estar ou não seguindo os caminhos e princípios corretos e ainda assim observando e analisando, se também recebe a assistência, atenção essencial para o seu aperfeiçoamento dentro do seu contexto educacional, como também encontra-se preparado para receber e absorver positivamente críticas que sirvam para rever questões que precisem de alguns ajustes importantes em beneficio seus alunos.

O fazer docente, vem sendo algo que traz consigo a necessidade de fazer a junção de teoria com a prática, já que uma precisa da outra simultaneamente, pois ao momento em que o professor pesquisa, ele buscar métodos para desenvolver conteúdos e melhorar a sua compreensão, posteriormente ele colocará em prática o seu período investigativo.

Percebe-se e compreende-se que há necessidade de se conhecer a relação teoria e prática, de maneira clara e objetiva buscando aperfeiçoamento constantemente, dando diariamente sentido ao conhecimento, aprendizado e inovação, onde a sua identidade profissional não poder ser vista como uma situação estável, fixa, mas uma complexidade, dinâmica onde a própria imagem tem que se harmonizar com uma variedade de papeis que o professor necessita desempenhar. 


\section{Obstáculos e Desafios do Ser Professor}

A interação entre professor e aluno vem se tornando mais dinâmica, devido aos avanços nos âmbitos social, educacional, tecnológico e de mercado. A atuação dos profissionais da área de educação vem se remodelando com a finalidade de atender às demandas dos alunos, não só transmitindo conhecimento, mas buscando a interação e estimulando os alunos para desenvolverem suas habilidades e a concretizarem iniciativas e sonhos.

Ser professor, muitas vezes é algo que muitas pessoas escolhem por vocação e encantamento do ato de transmitir conhecimento, sendo mediador entre os educandos e o mundo nas suas perspectivas, sonhos e amadurecimento, bem como o diário momento na troca de experiências e o estar em constante contato com indivíduos e o observar os diferentes perfis, formas de pensar, agir e interagir em grupo, pois:

Durante seu preparo, o futuro professor se capacita para, em sua prática
docente, compreender o universo cultural do aluno, a fim de que, juntos, a
partir do que conhecem, venham a se debruçar sobre os desafios que o
mundo Ihes apresenta, procurando respondê-los, e nesse esforço,
produzam novos saberes (ALVES, 2001, pg. 40).

Infelizmente existe um grande percentual de profissionais da educação, que fez esta escolha, simplesmente pelo comodismo e grandes possibilidades de ser inserido no mercado de trabalho com maior rapidez e conseguindo assim, comodidade e estabilidade financeira, não se preocupando com o conhecimento, aprendizagem e avanço dos seus alunos.

Estes profissionais facilmente podem ser identificados a medida que geralmente são aqueles que não buscam se reinventar, continuar estudando para capacitar-se cada vez mais no intuito de enriquecer positivamente o seu desempenho em sala de aula, como também aqueles que não aceitam críticas construtivas, sugestões e são contrários a novas formas de práticas metodológicas e avanços favoráveis ao desenvolvimento dos seus educandos.

A docência considerada como profissão é sustentada pelo processo de profissionalização, o qual atinge uma dimensão social e não apenas individual (IMBERNÓN, 2011) e que, deve ser intrínseca à formação do professor. 
Muitos são os obstáculos e desafios que encontraremos nesta caminhada profissional e que para alguns serão significativas reflexões e para outros a opção de sair deste cenário trabalhista e buscar um novo caminho a seguir.

Quando se aborda os obstáculos e desafios do ser professor, no primeiro momento compreende-se que se resume somente a instituição escolar e o ensinar aos alunos, mas o que ao decorrer do tempo se percebe que vai muito mais além e que se trata é de uma alta e grande complexidade, exigindo assim, reflexões, troca de ideias, sugestões e muita determinação.

Nos últimos anos, as transformações sociais políticas e econômicas tem sido tão acentuadas que os pontos de contato com a realidade atual são muito delicados. O professor encontra dificuldades em desenvolver seu trabalho de maneira prazerosa, objetiva e consistente. Sendo que em diversos momentos trava uma verdadeira luta e se percebe numa guerra diária entre o seu pensar e querer por pratica e a contrariedade de direção e coordenação ao discordarem do seu pensar e agir profissional, isto, quando não há diálogo construtivo, e abertura para a complementação e ajustes de ideias.

Uma grande interferência é a precariedade que muitas instituições de ensino se encontram, desde os materiais didáticos insuficientes para a realização de atividades diferenciadas como também para a culminância de projetos que serão benéficos para todos em especial para os alunos, que desenvolverão habilidade e terão a possibilidade de aperfeiçoar as que já possuem.

Privando assim, o aluno ao acesso a informações que os ajudarão a formar conceitos, discernir sobre diferenciados assuntos que serão fundamentais para a sua vivência em sociedade como o auxiliará na sua vida cotidiana, entre outros que ao passar do tempo aparecerão.

Diante de tantas transformações ocasionadas na área educacional e nas mudanças quanto ao cenário familiar, o profissional deve se preparar cada vez mais, e antes de tudo é preciso estar aberto para atuar em várias áreas e acompanhar os avanços e aperfeiçoar as relações humanas. Perante os desafios, pode-se citar a permanência do aluno na escola, onde de forma frequente acontece a evasão escolar, fruto de problemas sociais que afetam famílias de alunos e que nem a 
escola quanto o professor não possui meios para assegurar este aluno no âmbito escolar.

\section{Experiências Práticas}

No decorrer dos tempos, na vida de todo profissional, seja em qualquer campo trabalhista, as experiências adquiridas são fundamentais para cada vez mais se aperfeiçoar no que faz, vencer obstáculos, corrigir falhas e criar meios que possibilitem seu desempenho na obtenção de resultados significativos e o alcance de objetivos. Assim, no campo educacional, não vem a ser diferente uma vez que constantemente, o educador necessita de uma pratica pedagógica com maior consistência para que desta maneira, o mesmo consiga colocar em pratica muito do que viu na teoria e não teve a oportunidade de vivenciar para tirar suas próprias conclusões e fazer ajustes que muitas vezes acha necessário e discordava de alguns meios para construir o conhecimento e aprendizado dos alunos.

A comunicação e vivencia com os educandos pode ser vista como uma árdua, satisfatória e também prazerosa experiência para a estruturação da sua vida profissional, à medida que há muitas trocas, reflexões e modificações essências nos métodos de ensino, bem como leva a valiosas reflexões que transforma o educador na forma de pensar e agir com os seus alunos, uma vez que acontece a humanização e empatia, por ser indivíduos com diferentes perfis e realidades bem distante umas das outras, pois:

\footnotetext{
O papel do professor em todas as épocas é ser o arauto permanente das inovações existentes. Ensinar é fazer conhecido o desconhecido. Agente das inovações por excelência o professor aproxima 0 aprendiz das novidades, descobertas, informações e notícias orientadas para a efetivação da aprendizagem (KENSKI, 2001, p.103).
}

As experiências na prática são fundamentais, e complementam todo o vasto conhecimento adquirido pelo educador no tempo de graduação, e, portanto, ambas ao se cruzarem, acontecendo essa junção, ocorre o constante amadurecimento deste no âmbito educacional. Um dos grandes desafios a ser enfrentado na formação de professores é acabar com a ideia de um modelo único de ensino, sendo assim, o educador deve se colocar na posição de eterno aprendiz que busca uma formação profissional contínua. Pode-se desta forma, compreender que a educação se encontra num constante processo de transformações, que por sua vez, tentam acompanhar o ritmo do novo milênio. 
O educador vem exercendo um papel insubstituível no processo de transformação social, pois a formação de sua identidade ultrapassa o profissional, constituindo fundamentalmente a sua atenção profissional na prática social. Perante a tantas transformações, as quais todo o educador deve sempre estar atento e acompanhando, o professor do século XXI deve ser alguém que elabora com criatividade os conhecimentos teóricos e críticos sobre a realidade, tendo o mesmo que centrar-se numa prática pedagógica de êxito, com uma aprendizagem satisfatória e significativa. Pois as constantes mudanças ocorridas na sociedade exigem uma nova postura do professor, bem como um repensar crítico sobre a educação uma vez que:

Fazer da sala de aula o lugar de aprendizagem natural do sujeito é estabelecer como objetivo da escola criação de um ambiente onde se partilha e constrói significados. A decorrência de se aceitar esta afirmação como verdadeira é que aos que fazem a escola, cabe o planejamento de atividades de ensino mediante as quais, professores e alunos possam ampliar modificar e construir significados (MOURA, 2001, p.155).

Considerando experiências práticas como momentos fundamentais para conhecer, aprender e aperfeiçoar sua atuação, o exercício cotidiano vem a ser de extrema relevância a construção gradativa da sala de aula como um espaço onde acontece a interação entre todos. Ou seja, onde a ideia de um complementa o pensamento do outro, assim resultando em aprendizados que muitas vezes vão além do contexto preconcebido de ensino, se tornando ensinamentos que servirão para toda a vida.

Ao tempo em que está planejando, o professor, transcreve ações que ao seu olhar serão de grande relevância para seus alunos, mas em alguns momentos, não analisam que serão benéficos para ele próprio também. O educador em si, precisa ter sempre a consciência que não é detentor do conhecimento, que pode vir a cometer erros em algum momento, sendo algo que muitas vezes acontece e que está aprendendo sempre juntamente com seus alunos a cada dia e também a todo um novo tema que se trabalha principalmente de maneira pratica e não 'engessada', onde possibilita seus alunos participarem ativamente do conteúdo e ações propostas, por que:

O educador é um mediador do conhecimento, diante do aluno que é o sujeito da sua própria formação. Ele precisa construir conhecimento a partir do que faz e, para isso, também precisa ser curioso, buscar sentido para o que faz e apontar novos sentidos para o que fazer dos seus alunos (GADOTTI, 2000, p. 9). 
A busca de uma nova reflexão no processo educativo, onde o agente escolar passe a vivenciar essas transformações de forma a beneficiar suas ações podendo buscar novas formas didáticas e metodológicas de promoção do processo ensinoaprendizagem com seu aluno, sem com isso ser colocado como mero expectador dos avanços estruturais de nossa sociedade, mas um instrumento de enfoque motivador desse processo.

O educador precisa ter conhecimento sim, porém a construção de novos saberes é indispensável a qualquer indivíduo, pois esta construção não tem fim, precisa estar aberto para construir esse saber no seu cotidiano juntamente com os seus educandos sendo fundamental nos dias de hoje, já que o público estudantil, de acordo com as novas gerações sabem o que querem e gostam de direcionamentos não de ordens. Criar um clima onde os educandos possam expor suas opiniões, e que possibilitem desenvolver a autonomia e trocar conhecimentos é o que se precisa atualmente.

Se no passado os educadores tratavam todos da mesma forma, sem reconhecer os talentos individuais de cada um, ou estimular as capacidades, hoje essa prática esta inutilizada. A medida que os próprios educadores possuem uma nova postura e percebem o quanto é fundamental e enriquecedor para si mesmo, compreender e buscar satisfazer os anseios dos mesmos, para assim, ele percebe a importância do constante aprendizado não somente no setor profissional, mas também como algo que faz parte de toda a vida.

A prática pedagógica, portanto, relacionada aos objetivos planejados faz com que o professor consiga chegar a uma aprendizagem efetiva e significativa dentro do planejado, aguçando a permanência do aluno na escola, e, ainda, esse trabalho favorece o sistema educacional e a avaliação constante da atuação do professor em sala de aula. Conclui-se que nada está pronto e que o educador está em processo de redefinição da profissão e da compreensão da prática.

\section{A Importância da Formação Docente Para a Prática Pedagógica}

A formação docente para a prática pedagógica é primordial à medida que, é através desta que o futuro educador, terá embasamento teórico, para a sua pratica em sala de aula, como também terá a possibilidade em compreender os mecanismos que são utilizados para que haja a interação entre os educandos e o 
mundo através dos conteúdos trabalhados. Bem como a elaboração de projetos e ações que os aproximem da sua realidade, além de perceber os diversos caminhos que poderão ser seguidos para motivar e estimulá-los cada vez mais.

A formação do professor deve abranger uma dimensão pessoal, a qual necessita estimular reflexão crítica e autonomia nos docentes, além de encontrar espaços de interação entre o pessoal e profissional para que os professores possam dar significado e sentido às suas vivências. É com a construção do saber e do conhecimento na formação que se constitui a identidade docente (NÓVOA, 1995).

Entendemos que o docente se constitui a partir do momento em que se vivencia a relação dialética do processo de ensino e de aprendizagem, entre a concretude da sala de aula e os estudos acadêmicos na universidade.

Ao tempo em que o futuro docente busca se informar, capacitar e se qualificar, tende a desenvolver e consequentemente ter amadurecimento para uma atuação inicial no âmbito educacional. E ao passar do tempo o mesmo procura aprender e se aperfeiçoar através da contínua pratica, onde acontecerá a aquisição de significativos aprendizados, maior segurança em trabalhar diversos conteúdos e ocasionará uma crescente e saudável comunicação com seus educandos que vem a ser outro fator de considerável relevância para a vida profissional do educador.

Através da formação docente, o já atual ou futuro educador, poderá compreender as diversas concepções dos mais variados e famosos estudiosos acerca do campo educacional e suas maneiras de perceber a relação entre as fases do desenvolvimento humano e os tipos de aprendizagem. A escola desta forma tem uma grande amplitude de metas e objetivos a serem desenvolvidos junto aos seus alunos, e para que esse trabalho possa ser efetivo, recai sobre os professores a responsabilidade das ações a serem promovidas em sala de aula.

Terezinha Rios observa que a distância entre o saber e o não saber teria 0 poder de nos elevar, nos retirar de um lugar inferior e nos alçar a outro patamar. A autora, porém, questiona essa ideia, ao afirmar que o exercício de aprender é contínuo, não acaba nunca. Sempre podemos aprender mais e, assim, mudar mais uma vez de lugar. Nesse sentido, seria melhor considerarmos cada saber como um passo adiante no mesmo nível em que estamos um passo adiante como experiência 
diferente. Um passo adiante em um movimento contínuo espiral (PANNUTI, 2012, p.22).

O docente deve apresentar uma diversificação de saberes e habilidades que possibilitem concretizar a sua prática pedagógica na busca de atender o que se espera da escola e de seus professores. Diante dessa realidade é de grande relevância a formação docente no embasamento para uma prática docente mais completa possível, tonando-se essencial que o profissional da educação saiba os conceitos básicos, por exemplo, de educação, sociedade, aprendizagem e conhecimento para o êxito da sua atuação.

A atuação dos profissionais da área de educação vem se remodelando com a finalidade de atender às demandas dos alunos, não só transmitindo conhecimento, mas buscando a interação e estimulando os educandos para desenvolver suas habilidades e concretizarem iniciativas e sonhos.

A formação docente deste modo mostra ao profissional de educação o quanto é relevante a percepção de que educar não se resume apenas a passar conteúdos, mas sim aproximar-se cada vez mais dos alunos de maneira dinâmica e criativa, trabalhando sua realidade e considerando seus conhecimentos prévios.

Partindo desse princípio, constatamos que não existe fórmula pronta para a área educacional, são vários os caminhos que poderão ser utilizados para alcançar os objetivos traçados e para que tudo possa ser entendido, é necessário esforço, dedicação e comprometimento na perspectiva de que se tenha uma base solida composta de reflexões consistentes que o direcione de maneira clara e objetiva para uma pratica pedagógica que tenha embasamento e assim, o educador sinta-se seguro e transmita segurança para seus alunos.

\section{Considerações Finais}

A prática pedagógica na Educação Infantil, as relações dos educadores com as crianças e os diversos universos sociais nos quais elas interagem, possibilita a criação de condições para que elas possam, gradativamente, desenvolver capacidades ligadas à tomadas de decisões, à construção de regras, à cooperação, solidariedade, ao diálogo, ao respeito a si mesmas e ao outro, assim como 
desenvolver sentimos de justiça e ações de cuidado para consigo e para com os outros.

Em relação às regras, além de se manter a preocupação quanto à clareza e a transparência na sua apresentação e à coerência das sanções, é preciso dar oportunidade para que as crianças participarem do estabelecimento de regras que irão afetar-lhes diretamente. A prática pedagógica motivada nas brincadeiras constitui uma forma prazerosa para a criança entender a funcionalidade do mundo que está inserida.

As atividades lúdicas propiciam a construção da identidade da criança através do brincar pontuada nas experiências e vivencias no espaço de aprendizagem, principalmente na Educação Infantil. Visto que a criança dedica a maior parte de seu tempo ao brincar

\section{Referências:}

ALVES, R. Filosofia da Ciência: Introdução ao jogo e suas regras. São Paulo: Editora Loyola, 2001.

FERNANDES, T. M. Professora de Educação Infantil: dilemas da constituição de uma especificidade profissional. Um estudo sobre a produção científica brasileira (1996-2009). Catarina Florianópolis: UFSC, 2010.

FREIRE, P. Pedagogia da autonomia: saberes necessários à prática educativa. São Paulo: Paz e Terra, 1993.

GADOTTI, M. Perspectivas atuais da educação. Porto Alegre, Ed. Artes Médicas, 2000

IMBERNÓN, F. Formação docente e profissional: formar-se para a mudança e a incerteza. 9. ed. São Paulo: Cortez, 2011.

KLEINKE, R. C. M.. Aprendizagem significativa: uma pedagogia por projetos no processo de alfabetização. Florianópolis: UFSC, 2003.

MOURA, M. A atividade de ensino como unidade formadora. Bolema: São Paulo. 1996

NÓVOA, A. Formação de professores e profissão docente. In: NÓVOA, A. Os professores e sua formação. 2. ed. Lisboa: Dom Quixote, 1995.

OLIVEIRA, Z. R. et. al. O trabalho do professor na Educação Infantil. São Paulo: Editora Biruta, 2012. 
PANNUTI, D. Interações: encontros de leitura e escrita. Coleção InterAções São Paulo: Blucher, 2012

TARDIF, M. Saberes profissionais dos professores universitários: elementos para uma epistemologia da prática profissional dos professores e suas consequências em relação à formação para o magistério. [s.l]:Revista Brasileira de Educação, [s.l]:2000.

TORRES, C. M. G; CARNEIRO, C. C. B. S. Diretrizes Curriculares e identidade docente de professores de ciências biológicas. [s.I]:Revista da SBEnBIO, 2014. 